\title{
Applying LCA to Estimate Development Energy Needs: The Cases of India and Brazil
}

\author{
Narasimha D. Rao, Alessio Mastrucci and Jihoon Min
}

\begin{abstract}
This paper illustrates the use of life cycle assessment (LCA) methods to link human wellbeing to resource consumption. Based on a previously developed framework of the material requirements for human well-being, we use LCA and Input-Output (I/O) analysis, as appropriate, to estimate the life-cycle energy needed to meet the gap in living standards in two emerging economies, India and Brazil. We illustrate the relative contribution of different living standards components to energy requirements, as well as the uncertainty and trade-offs between upfront and long-term operating energy costs, and how these factors differ in the two countries. This analysis provides insights on how LCA analysis can be used to inform energy planning and its links to development goals.
\end{abstract}

\section{Introduction}

There is much potential for life cycle assessment (LCA) to inform public policy beyond its traditional use to address environmental objectives [1]. This paper illustrates how LCA can be used to inform development and energy policies related to improving living standards in emerging economies. Our motivation is that technology, material and design choices in the build-up of infrastructure can present important trade-offs between short-term (construction) and long-term (operating) energy needs, as well as different net energy requirements. These differences matter in emerging economies such as India and Brazil that expect high future economic growth and significant infrastructure investments. The Indian government anticipates 1.5 trillion dollars of infrastructure investments over the next decade [2]. Furthermore, almost a quarter of the building stock ( $\sim 50$ million units), requires upgrading [3], not counting population growth and future migration to urban areas.

N. D. Rao $(\varangle) \cdot$ A. Mastrucci · J. Min

International Institute for Applied Systems Analysis (IIASA),

Energy (ENE) Program, 2361 Laxenburg, Austria

e-mail: nrao@iiasa.ac.at

(C) The Author(s) 2018

E. Benetto et al. (eds.), Designing Sustainable Technologies,

Products and Policies, https://doi.org/10.1007/978-3-319-66981-6_44 
Brazil is a useful contrast, as it faces similar social challenges, such as high inequality, but a very different scale and with different resource endowments.

Based on a previously developed account of decent living standards ("DLS"), which define the material requirements for human wellbeing [4], we use LCA and Input-Output (I/O) analysis, as appropriate, to estimate the life-cycle energy required to meet the gap in, and sustain, DLS for all. We consider the energy associated with delivering DLS goods and services, including food production and preparation, clothing, housing, the extension of networks for water and sanitation, electricity, social infrastructure (health and education), communications, roads and transport systems. Our emphasis in this study is on methodology, not on empirical findings. That is, rather than supplying comprehensive estimates on the energy requirements for providing DLS, we aim to illustrate how LCA methods can be used to provide insights into such a quantification exercise. We make three contributions in this regard: (a) we illustrate the relative contributions of living standard components to the estimation of energy requirements for a DLS; (b) we show how uncertainty can be systematically quantified and attributed to these choices; and (c) we show the trade-offs in construction and operating energy inherent in these choices.

\section{Methods}

The methodology includes three steps: estimation of the gaps in DLS; calculation of life-cycle material and energy requirements; uncertainty analysis.

First, we estimate the gaps in DLS (Sect. 3) in material terms, such as the number of housing units for shelter, toilets for sanitation, minimum water consumption for water supply, basic appliances, etc. based on national and international sources. The key components of the DLS can be inferred from the normative standards in Table 1. A more comprehensive description can be found in Rao and Min [4].

These normative standards are converted into material requirements, the process of which is straightforward except for social dimensions of wellbeing (health and education), whose material needs are not easily determined. For these, we rely on previous empirical analysis [4] to determine the national expenditure levels required at a minimum to achieve standards of primary education and life expectancy respectively. We use a multi-region input-output (MRIO) to estimate the energy requirements associated with this expenditure. We also use MRIO for food production, whose heterogeneity across the economy is best aggregated through an MRIO.

For material items in the DLS, such as housing, appliances and related infrastructure, we use traditional LCA calculations [5]. For housing, we identify building archetypes representative of different climatic conditions, regions (e.g. depending on material availability) and urban/rural areas and we calculate construction and operational energy using a material inventory and a dynamic energy model. Using 
Table 1 Sources of uncertainty in assessing decent living standard (DLS) energy requirements

\begin{tabular}{|c|c|c|c|c|}
\hline Sector & DLS normative standard & Technology & Behavior & Geography \\
\hline $\begin{array}{l}\text { Food (production, } \\
\text { preparation, } \\
\text { conservation) }\end{array}$ & $\begin{array}{l}\text { Calorie requirement, } \\
\text { modern } \\
\text { cook stoves, refrigerators }\end{array}$ & $\begin{array}{l}\text { Efficiency of } \\
\text { refrigerators and } \\
\text { cook stoves }\end{array}$ & Diet & \\
\hline Clothing & Minimum clothing & & & \\
\hline Housing & $\begin{array}{l}\text { Minimum floor space, } \\
\text { safety, thermal and visual } \\
\text { comfort }\end{array}$ & $\begin{array}{l}\text { Materials } \\
\text { Lighting } \\
\text { technology }\end{array}$ & $\begin{array}{l}\text { Cooling } \\
\text { schedules }\end{array}$ & $\begin{array}{l}\text { Climatic } \\
\text { zone }\end{array}$ \\
\hline Water/Sanitation & $\begin{array}{l}\text { Minimum water, in-house } \\
\text { sanitation }\end{array}$ & $\begin{array}{l}\text { Water supply } \\
\text { system } \\
\text { configuration }\end{array}$ & & $\begin{array}{l}\text { Water } \\
\text { source } \\
\text { distance }\end{array}$ \\
\hline Health & $\begin{array}{l}\text { Life expectancy, number } \\
\text { of hospital beds }\end{array}$ & Expenditure/cap & & \\
\hline Education & $\begin{array}{l}\text { Primary/secondary } \\
\text { attainment }\end{array}$ & Expenditure/cap & & \\
\hline Communication & Access to TV & Efficiency & TV hours & \\
\hline $\begin{array}{l}\text { Mobility (transport, } \\
\text { roads) }\end{array}$ & $\begin{array}{l}\text { Access to motorized } \\
\text { transport }\end{array}$ & $\begin{array}{l}\text { Mode shares, } \\
\text { vehicle } \\
\text { efficiency, fuels }\end{array}$ & & \\
\hline
\end{tabular}

Entries in bold are illustrated in this study

this bottom-up simulation model [6] we are able to assess the influence of material, technology and design choices on both construction and operating energy requirements and finally extrapolate results to the national level. For some of the sectors, e.g. water supply and sanitation, where building a comprehensive LCA model would be out of the scope of this study, we rely instead on a set of international studies to assess the range of construction and operational energy intensities corresponding to different technologies and contextual conditions. Illustrative results of the energy requirements in different sectors for India and Brazil are shown in Sect. 4.

Uncertainty in energy estimates can arise from a number of inputs, which to yield total uncertainty. Table 1 sketches out the key dimensions of uncertainty: the extent of the gap in DLS; technology performance; and human behaviour. There may be cases where multiple estimation approaches can be used, which contribute model uncertainty. However, we do not include such cases in this study.

As indicated in the table, we use the housing and water supply analysis as the primary vehicle to illustrate the different contributions to uncertainty (Sect. 5). For each case, we varied one parameter at a time according to suitable ranges of values to obtain the total range of variation in life-cycle energy. In all other cases, we use 'status quo' conditions to quantify energy needs, to reflect present-day habits and culture and commercially available technologies. 


\section{Gaps in Decent Living}

Figure 1 compares the gaps in DLS between India and Brazil. Indians lag in all dimensions by a significant margin. Over $90 \%$ of Brazilians have access to most components of DLS, while access to DLS in India ranges from as low as $17 \%$ (refrigerators) to $100 \%$ having primary education. The main implication of this for LCA and its value to energy planning is that in India a more significant component of future energy requirements stem from the construction of new infrastructure. The assessment of the cost-performance trade-offs of either leapfrogging to new technologies at a significant cost as opposed to scaling up living standards quickly and at relatively low cost but 'locking-in' to less efficient technology becomes critical in countries like India. The uncertainty in energy demand may also be higher, which depends to a greater extent on the nature and extent of population growth, migration to cities, and the evolution of technology.

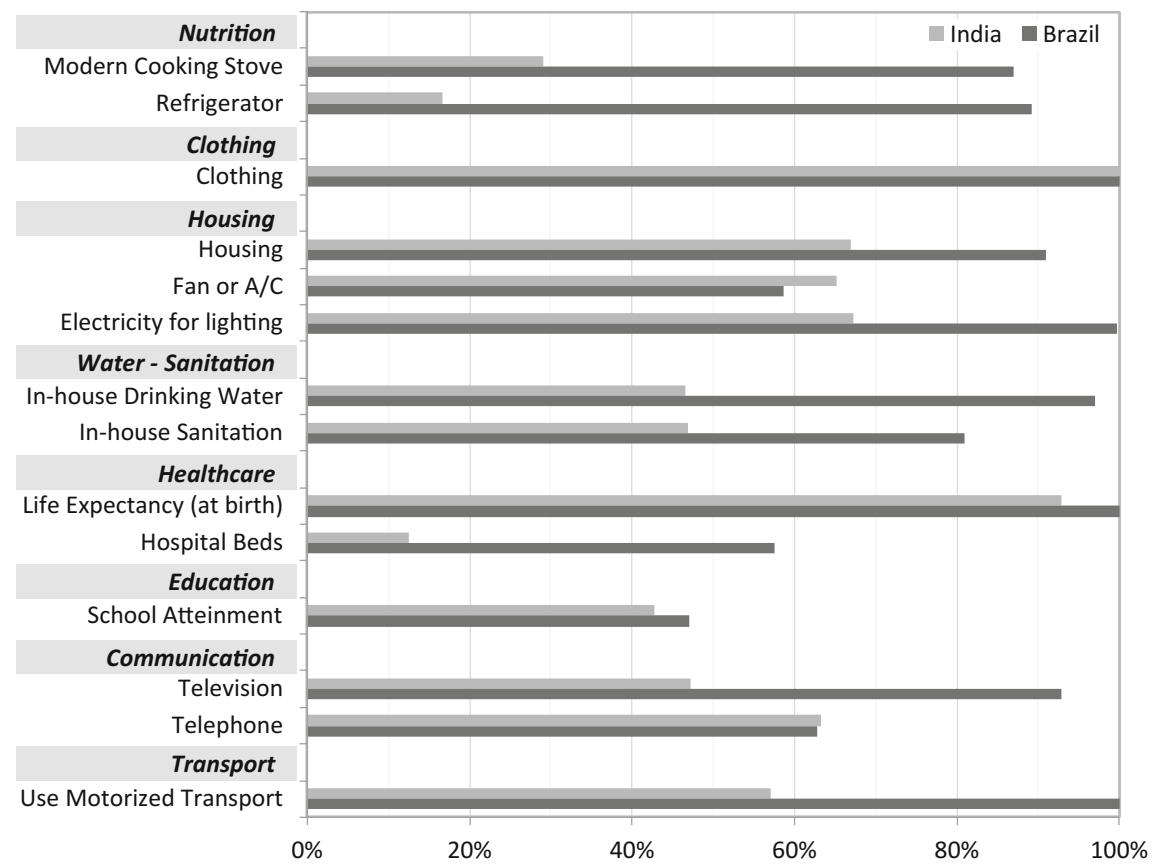

Fig. 1 Share of population with decent living conditions in India and Brazil. Notes life expectancy is a national average, shown as a proportion of 72 years $(100 \%)$; hospital beds are number per 1000 people, shown as a proportion of 2.2 (100\%). Sources IEA World Energy Outlook (2016); Census India (2011); UNICEF; National Health Profile 2010 (India); CIA The World Factbook; UNESCO; Seventh All-India Education Survey; NSSO 11-12 survey (India); POF 08-09 survey (Brazil); World Bank-Rural access index 


\section{Trade-off Between Embodied and Operational Energy}

Figure 2 illustrates the per capita operational, capital turnover, and total energy required for each DLS component in India and Brazil respectively. Note that both the operational and capital turnover energy represent a future scenario where
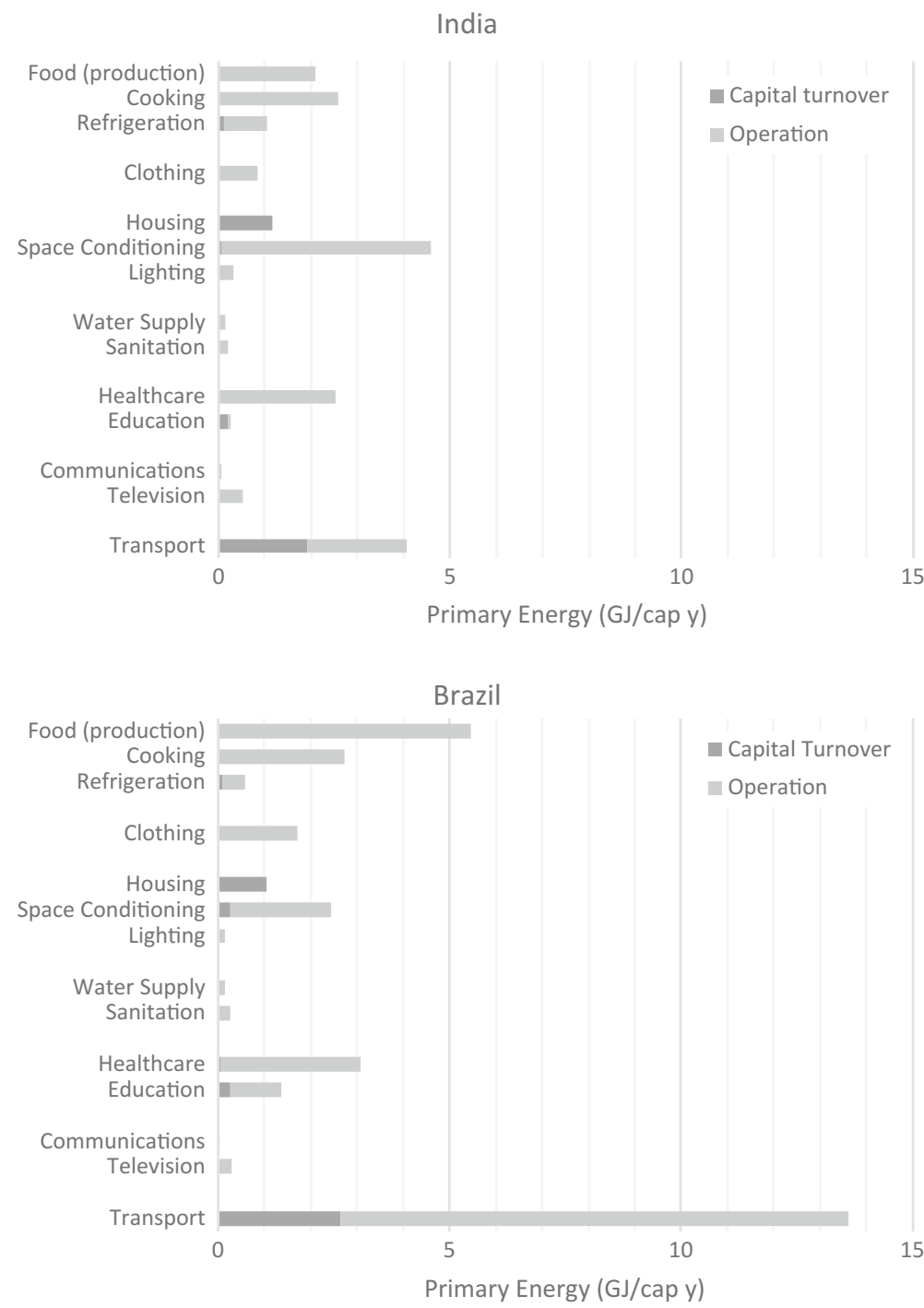

Fig. 2 Illustrative energy requirements to provide decent living standards in India and Brazil, showing capital turnover and operating energy. Note Space conditioning includes hot water production 
infrastructure gaps to manufacture and deliver the DLS products/services have been filled. Many of these results are still preliminary, and not meant to convey an empirical finding. Rather, they illustrate the kinds of insights such analysis enables. For instance, the relative energy requirements for different DLS components differ widely. Food in Brazil is far more energy intensive than in India, most likely due to the preponderance of meat consumption in Brazil compared to India. The housing energy requirement in India has a moderately higher share of capital turnover from the expansion of the existing stock. However, the energy required to heat and cool (largely cool) buildings is far greater in India due to, among other things, severe climatic conditions (high temperatures and humidity). In both countries, energy for overall capital expansion is dominated by housing and transportation.

Some caveats are in order. In general, in using existing country-specific data on material and energy intensities to meet a single standard, we can't discern whether differences arise from different levels of service quality, differences in energy needs, or differences in efficiency. For instance, health and education energy requirements in Brazil are higher than in India, because energy intensity levels in Brazil are significantly higher. This may imply that quality is higher, or that existing conditions (e.g., population density) may necessitate higher energy intensities in Brazil, or that energy use is less efficient in Brazil. In subsequent work, some discernment will be possible, based on deeper analysis of the health and education sectors.

Another caveat is that the electricity demand growth assumes power plants already exist (that is, the embedded energy associated with building new electric power plants to meet incremental electricity demand has not as yet been included). This is, however, typically very small in comparison to operating energy.

\section{Uncertainty Analysis}

An important aspect of energy demand estimation is uncertainty and its attribution to policymakers' decision variables. We illustrate this for the case of housing and water, which differ in the extent of influence of geography.

\subsection{Housing Supply Energy Requirements}

For housing, climatic conditions and building materials (accounting for local availability) are key sources of uncertainty and are analysed in this section (see Table 1 for all sources of uncertainty). We include country-specific options of traditional mud-based construction in India, and wooden homes in Brazil. For this paper, we use a single-storey building archetype for an average family in each country. Due to different average household sizes, the sample house is $30 \mathrm{~m}^{2}$ in Brazil and $40 \mathrm{~m}^{2}$ in India. Figure 3 shows the results, where the bars in the 
Fig. 3 Life-cycle energy requirements of housing with different construction technologies and materials. Whiskers reflect the range of climatic conditions

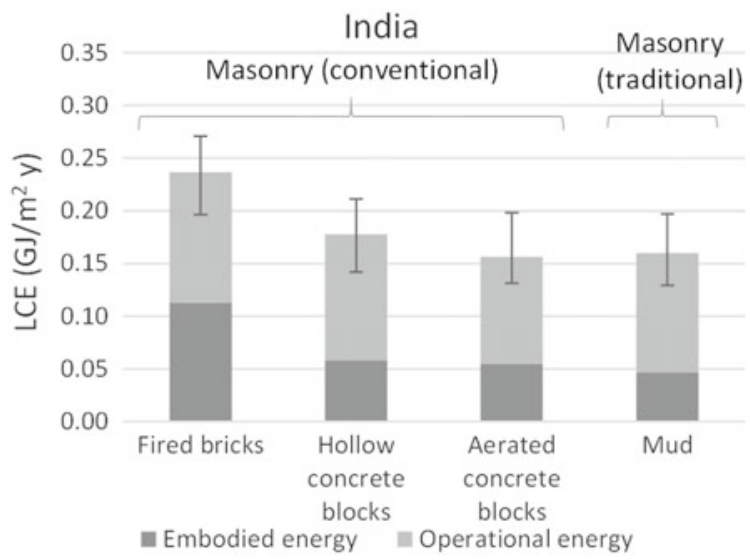

(a) India - Reference climatic zone is 'composite climate' (location: Allahabad).

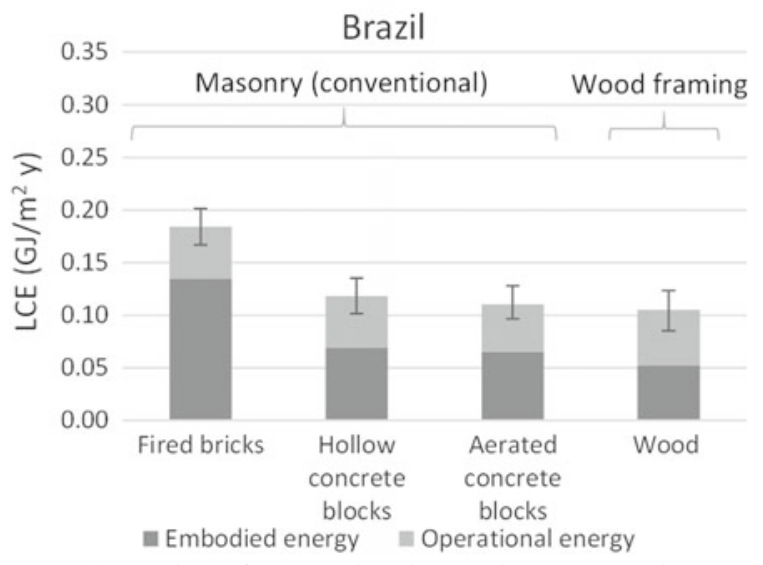

(b) Brazil - reference climatic zone is warm-humid (location: Belem).

histogram indicate energy requirements for different building technologies, and the whiskers show the range of variation in operating energy covering all climate conditions in both countries.

An important takeaway regarding the use of traditional mud housing in India is that despite moderately higher operating energy (due to poorer thermal insulation of the building), the savings in construction energy lead to a net energy reduction in comparison to fired bricks, the most common choice of construction today. Furthermore, the most efficient (aerated concrete blocks) has very marginally lower overall energy requirements than the least efficient (traditional mud) technology. However, aerated concrete is likely to be far more expensive than traditional mud. 
On an energy cost basis, therefore, this preliminary analysis would suggest that the traditional mud option may be the most favourable option compared to the present technology of choice, fired bricks. Other inconveniences, such as water penetration and termite attack, may, however, limit its application. Another insight is that the difference in total energy requirements is driven almost entirely by construction energy differences. The variation in operating energy is much smaller. One implication of this finding is that the favourable choice of construction materials is unlikely to vary much across India due to varying climate conditions. However, if one were to consider a broader range of energy savings measures (e.g. thermal insulation, high-performance glazing, shading devices, etc.) operational energy reductions may have a more influential role.

In Brazil, building operating energy is even less important than in India, due to more moderate climatic conditions. The variation in energy from the heterogeneity of climatic conditions in the country is correspondingly lower as well. Notably, the building materials show similar relative merits with respect to total energy requirements, with the exception that the traditional (in this case, wood) housing is even more favourable, having the least total energy requirement.

\subsection{Water Supply Energy Requirements}

Key sources of uncertainty for water supply include the geography and normative standard for water demand. We compare two different systems with different geographies - one with low water conveyance (in South Africa [7]), and another with high conveyance requirements (in Florida [8]). We also vary the normative standard for water demand, between a normative minimum of 501 per cap per day [9], and a reference of 100 1/cap/day (representing approximately the average demand in India). Notably, nothing in this analysis is actually dependent on local conditions in India or Brazil, so we show only one set of results.

In contrast to housing, water energy requirements are almost entirely composed of operating energy, which comprises pumping water through the distribution system and treating water. In this sector, construction materials matter far less than pumping technology and location. The range of variation for the two systems is higher than the mean. There may well be other locations in these countries that entail even higher conveyance costs (Fig. 4). 
Fig. 4 Water supply in India and Brazil. The bars show different normative requirements; the whiskers show the impact of source water distance

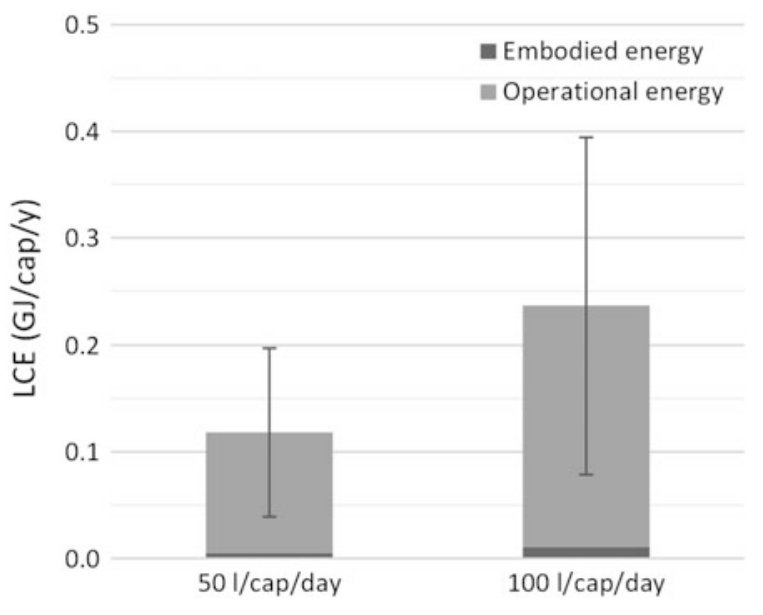

\section{Conclusions}

This paper illustrated the use of LCA methods to link human wellbeing to resource consumption. This linkage enables sectoral LCA analyses to be integrated and compared for use in holistic development policy planning. This provides policymakers with insights on trade-offs, and helps assign priorities among sectors. We illustrate the relative contribution of technological uncertainty in different sectors, as well the trade-offs between upfront and long-term operating energy costs. We also show how these trade-offs differ in different geographic conditions, illustrated with India and Brazil.

We did not aim for this study to provide comprehensive empirical findings on development energy needs-for instance, we do not include here the energy associated with building out infrastructure to meet development gaps - rather, we focused on annual energy outflows and their drivers. We illustrate, nevertheless, several empirical insights. For instance, the transport sector dominates energy needs to meet a basic living standard in Brazil, but not in India. In both country we show that traditional building materials in the long term may offer a win-win for both reducing energy use and costs of housing.

\section{References}

1. Finnveden G, et al., Recent developments in Life Cycle Assessment, Journal of Environmental Management, Vol. 91, 2009, pp. 1-21.

2. http://economictimes.indiatimes.com/news/economy/infrastructure/india-needs-1-5-trillion-forinfrastructure-arun-jaitley/printarticle/52922015.cms, (Accessed 15.06.2017).

3. Tiwari P, Rao J, Day J, Development Paradigms for Urban Housing in BRICS Countries. 2016. 
4. Rao N.D, Min J, Decent Living Standards: material prerequisites for human wellbeing, Soc Indic Res, 2017.

5. Buyle M, Braet J, Audenaert A, Life cycle assessment in the construction sector: A review, Renew Sust Energ Rev, Vol. 26, 2013, pp. 379-388.

6. Mastrucci A, Rao N.D, Decent housing in the developing world: Reducing life-cycle energy requirements. Energ. Buildings, Vol. 152, 2017, pp. 629-642.

7. Friedrich E, Life-cycle assessment as an environmental management tool in the production of potable water, Water Sci Technol, Vol. 46, No. 9, 2002, pp. 29-36.

8. Mo A, et al., Embodied energy comparison of surface water and ground-water supply options, Water Res, vol. 45, no. 17, 2011, pp. 5577-5586.

9. Gleick P, The human right to water. Water Policy, 1, 1998, pp. 487-503.

Open Access This chapter is licensed under the terms of the Creative Commons Attribution 4.0 International License (http://creativecommons.org/licenses/by/4.0/), which permits use, sharing, adaptation, distribution and reproduction in any medium or format, as long as you give appropriate credit to the original author(s) and the source, provide a link to the Creative Commons license and indicate if changes were made.

The images or other third party material in this chapter are included in the chapter's Creative Commons license, unless indicated otherwise in a credit line to the material. If material is not included in the chapter's Creative Commons license and your intended use is not permitted by statutory regulation or exceeds the permitted use, you will need to obtain permission directly from the copyright holder. 